\title{
Isokotomolide A from Cinnamomum kotoense Induce Melanoma Autophagy and Apoptosis In Vivo and In Vitro
}

\author{
Jian Li, ${ }^{1}$ Chung-Yi Chen, ${ }^{2}$ Jyun Yin Huang, ${ }^{3}$ Lin Wang, ${ }^{4}$ Zixuan $X{ }^{1},{ }^{1}$ Wenyi Kang, ${ }^{5}$ \\ Miao-Hsia Lin, ${ }^{6}$ and Hui-Min David Wang ${ }^{1,3,7,8}$ \\ ${ }^{1}$ College of Food and Biological Engineering, Jimei University, Xiamen 361021, China \\ ${ }^{2}$ Department of Nutrition and Health Science, School of Medical and Health Sciences, Fooyin University, Kaohsiung 831, Taiwan \\ ${ }^{3}$ Graduate Institute of Biomedical Engineering, National Chung Hsing University, Taichung 402, Taiwan \\ ${ }^{4}$ College of Chemistry \& Pharmacy, Northwest A\&F University, Yangling, Shaanxi 712100, China \\ ${ }^{5}$ Joint International Research Laboratory of Food \& Medicine Resource Function, Henan Province, Henan University, \\ Kaifeng 475004, China \\ ${ }^{6}$ Graduate Institute of Microbiology, College of Medicine National Taiwan University, Taipei 100, Taiwan \\ ${ }^{7}$ Graduate Institute of Medicine, College of Medicine, Kaohsiung Medical University, Kaohsiung 807, Taiwan \\ ${ }^{8}$ Department of Medical Laboratory Science and Biotechnology, China Medical University, Taichung City 404, Taiwan
}

Correspondence should be addressed to Hui-Min David Wang; davidw@dragon.nchu.edu.tw

Received 22 June 2020; Revised 24 August 2020; Accepted 11 September 2020; Published 27 September 2020

Academic Editor: Daoud Ali

Copyright (C) 2020 Jian Li et al. This is an open access article distributed under the Creative Commons Attribution License, which permits unrestricted use, distribution, and reproduction in any medium, provided the original work is properly cited.

Melanoma is an aggressive cancer with high lethality. In order to find new anticancer agents, isokotomolide A (Iso A) and secokotomolide A (Sec A) isolated from Cinnamomum kotoense were identified to be potential bioactive agents against human melanoma but without strong antioxidative properties. Cell proliferation assay displayed Iso A and Sec A treated in the normal human skin cells showed high viabilities. It also verified that two of them possess strong antimelanoma effect in concentrationdependent manners, especially on B16F10, A2058, MeWo, and A375 cells. Wound healing assay presented their excellent antimigratory effects. Through 3-N,3-N,6-N,6-N-Tetramethylacridine-3,6-diamine (acridine orange, AO) staining and Western blot, the autophagy induced by treatment was confirmed, including autophagy-related proteins (Atgs). By using annexin VFITC/PI double-stain, the apoptosis was confirmed, and both components also triggered the cell cycle arrest and DNA damage. We demonstrated the correlations between the mitogen-activated protein kinase (MAPK) pathway and antimelanoma, such as caspase cascade activations. To further evaluate in vivo experiments, the inhibition of tumor cell growth was verified through the histopathological staining in a xenograft model. In this study, it was confirmed that Iso A and Sec A can encourage melanoma cell death via early autophagy and late apoptosis processes.

\section{Introduction}

Skin cancer is one of the most aggressive malignant tumors, which especially occurs in people with light skin. The primary reason of skin cancer is the overexposure to ultraviolet (UV) radiation [1]. Chemical mutagens, genetic susceptibility, human papillomavirus, and tobacco consumption can also lead to skin cancer. In addition, the utilization of immunosuppressive drugs such as azathioprine and cyclosporine $\mathrm{A}$ has been reported to result in the occurrence of skin cancer [2]. There are three skin cancers: squamous cell carcinoma
(SCC), basal cell carcinoma (BCC), and malignant melanoma. BCC grows slowly and can damage the surrounding tissue, but it does not have the ability to spread to other areas. SCC is a kind of abnormal cell cancer with uncontrolled growth arising from the squamous cells. It can occur in all areas of the body and are the most common in the areas exposed to sunlight. SCC possesses the ability of metastasis and can harm other areas of the body. BCC and SCC are defined as nonmelanoma skin cancer (NMSC) [3]. Malignant melanoma is highly aggressive which develops from the pigment-containing cells known as melanocytes. Melanoma 
can spread rapidly through the whole body of the patient, and thus causes a very low survival rate [4].

The most effective method to prevent skin cancer is avoiding exposure to UV radiation and using sunscreen. If the skin cancer occurs, in the initial stage, it can be curable by surgical elimination, while in the advanced stage, it is usually treated by immunotherapy and chemotherapy [5]. The classical pharmacotherapy employed for the treatment of skin cancers usually includes 5-fluorouracil, imiquimod, diclofenac, and ingenol mebutate. In recent years, the phytochemicals such as quercetin, epigallocatechin-3-gallate, resveratrol, and curcumin have been applied in the melanoma treatment [6-8].

The mitogen-activated protein kinase (MAPK) cascade activation is the center of various signaling pathways. It plays an important role in receiving the membrane receptors to convert and transmit signals into the nucleus. There are three different pathways of MAPKs, i.e., the extracellular-signalregulated kinase (ERK), c-Jun N-terminal kinase (JNK), and p38 MAPK. The JNK pathway is known to regulate the cell growth and death, however, the mechanism of how the JNK/MAPK signaling pathway inhibits the melanoma has not been fully clarified. This study was aimed at figuring out the naturally occurring chemotherapeutic agent and evaluated their cytotoxicity on melanoma. Cinnamomum kotoense Kanehira is a kind of Lauraceae evergreen small tree, which is native to Lanyu Island, a small island of southeast Taiwan. The bark is used as medicine to prevent colds, pain, bleeding, and so on. It is also rich in cinnamon oil to be the main component as cinnamaldehyde and exudes fragrance to clean air. Iso A and Sec A were constitutes isolated from the leaves of Cinnamomum kotoense (Figure 1). A previous study had shown that Iso A was an agent capable of inducing human nonsmall lung cancer apoptosis [9]. Iso A and Sec A also exhibited cytotoxicity on Hela cells [10]. In this study, a hypothesis was proposed that both components were potential elements against the melanoma cells to investigate the possible antimelanoma mechanism. We investigated the effects of Iso A and Sec A on the suppressions in cellular proliferation, cell cycle arrest, cell migration, and the activations of autophagy and apoptosis pathways, and in vivo examinations.

\section{Materials and Methods}

2.1. Materials and Reagents. Vitamin C, ethylene diamine tetraacetic acid (EDTA), butyl hydroxy anisd (BHA), trichloroacetic acid, potassium ferricyanide, $\mathrm{FeCl}_{3}, \mathrm{FeCl}_{2} \cdot 4 \mathrm{H}_{2} \mathrm{O}, 3-(4$, 5-Dimethylthiazol-2-yl)-2, 5-diphenyltetrazolium bromide (MTT), dimethyl sulfoxide (DMSO), Dulbecco's modified Eagle's medium (DMEM), fetal bovine serum (FBS), Trpsin-0.5\%EDTA, and phosphate-buffered saline (PBS). Antibodies against $\beta$-actin, cleaved caspase 3, 9, and peroxidase-conjugated anti-rabbit IgG secondary antibody were purchased from cell signaling (Beverly, MA, USA). Antibodies of B-cell lymphoma 2 (Bcl-2), JNK, Beclin-1 (Atg-6), Atg 5, 10, and 16 were purchased from ABGENT Co. (San Diego, CA, USA). Peroxidase-conjugated antimouse IgG secondary antibody was purchased from Pierce
(Rockford, IL, USA). All the other chemicals and reagents were purchased from Sigma Chemical (St. Louis, MO, USA).

2.2. Extraction and Isolation of Compounds. The air-dried leaves of Cinnamomum kotoense $(11.0 \mathrm{~kg})$ were extracted with $\mathrm{MeOH}(80 \mathrm{~L} \times 6)$ at room temperature, and the $\mathrm{MeOH}$ extract $(201.2 \mathrm{~g})$ was obtained upon the concentration under reduced pressure [9]. The $\mathrm{MeOH}$ extract, suspended in $\mathrm{H}_{2} \mathrm{O}$ ( $1 \mathrm{~L}$ ), was partitioned with $\mathrm{CHCl}_{3}$ to give fractions soluble in $\mathrm{CHCl}_{3}$ and $\mathrm{H}_{2} \mathrm{O}$. The $\mathrm{CHCl}_{3}$-soluble fraction was chromatographed over silica gel using $n$-hexane-EtOAc-acetone as an eluent to produce five fractions. Part of fraction 1 was subjected to $\mathrm{Si}$ gel chromatography by eluting with $n$-hexaneEtOAc, and then enriched with EtOAc to furnish 10 fractions. Fraction 1-1 was resubjected to Si gel chromatography, eluting with $n$-hexane-EtOAc, and enriched gradually with EtOAc to obtain five other fractions. Fraction 1-1-2 eluted with $n$-hexane-EtOAc was further separated using silica gel column chromatography and preparative thin-layer chromatography (TLC), giving Sec A (327 mg). Part of fraction 2 was subjected to Si gel chromatography by eluting with $n$-hexaneEtOAc and enriched with EtOAc to furnish six fractions. Fraction 2-3 was resubjected to Si gel chromatography, eluting with $n$-hexane-EtOAc, and enriching gradually with EtOAc to obtain four fractions [11]. Fraction 2-3-2 eluted with $n$-hexane-EtOAc was further separated with silica gel column chromatography and preparative TLC ( $n$-hexaneEtOAc; and gave Iso A).

2.3. 1, 1-Diphenyl-2-Picrylhydrazyl (DPPH) Radical Scavenging Activity. DPPH is an unstable radical and has a strong absorbance at $517 \mathrm{~nm}$, when DPPH is reduced by an antioxidant or combined with another free radical, its absorbance will be reduced or even disappear [11]. Thus, DPPH is applied to examine the antioxidant activity by detecting radical scavenging capability. Briefly, added $1.0 \mu \mathrm{L}$ accurate concentration $(10,50,100$, and $200 \mu \mathrm{M})$ of Iso A or Sec A to $99 \mu \mathrm{L} \mathrm{DPPH}(60 \mu \mathrm{M})$. In addition, the positive control was vitamin $\mathrm{C}$, because of its excellent antioxidant activity. We detected the absorbance value at $517 \mathrm{~nm}$; the radical scavenging capability (percentage) was calculated by formula as follows:

Radical scavenging $\operatorname{activity}(\%)=\frac{\left(A_{\text {control }}-A_{\text {sample }}\right)}{A_{\text {control }}} \times 100 \%$.

2.4. Metal Chelating Activity. Metal ion is one of the causes for the lipid peroxidation, especially ferrous ion which is prooxidant. This assay is based on the complexes of ferrous ions and ferrozine have a color reaction at $562 \mathrm{~nm}$, and the lower absorbance means the better metal chelating activity [12]. $1.0 \mu \mathrm{L}$ various dosages $(10,50,100$, and $200 \mu \mathrm{M})$ of Iso $\mathrm{A}$ or Sec A were added into $10 \mu \mathrm{L} \mathrm{FeCl} \cdot 4 \mathrm{H}_{2} \mathrm{O}(2.0 \mathrm{mM})$ to mix with $20 \mu \mathrm{L}$ ferrozine $(5.0 \mathrm{mM})$, and EDTA acted as a positive control. The absorbance of the mixture was observed at $562 \mathrm{~nm}$. The chelating power activity was calculated as Equation (1): 


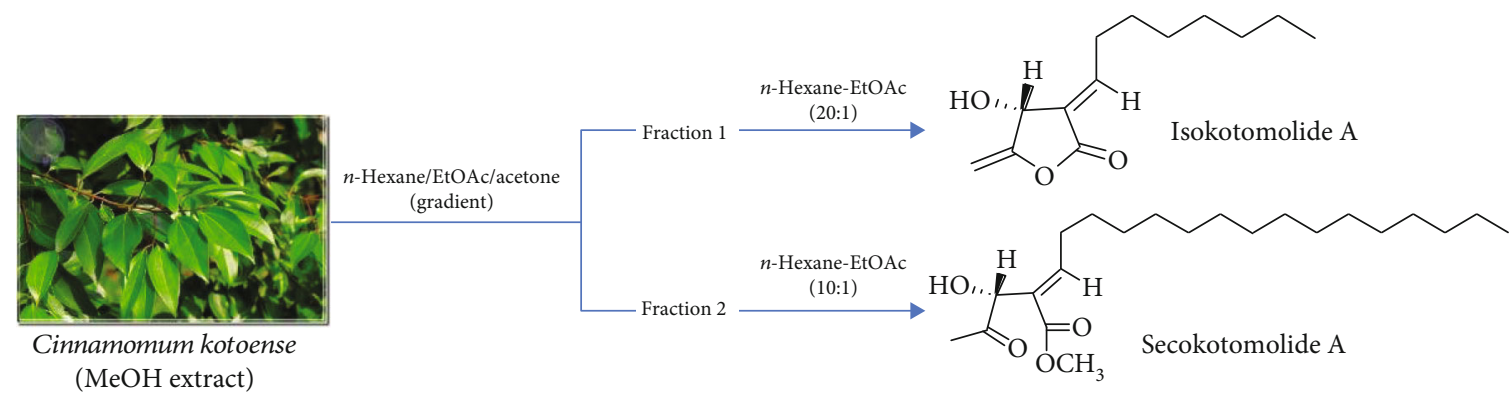

FIgURE 1: The purification and chemical structures of Iso A and Sec A.

2.5. Reducing Power. We used the reduce power assay to test the reductive ability of Iso A and Sec A. Briefly, $85 \mu \mathrm{L}, 0.2 \mathrm{M}$ phosphate buffer ( $\mathrm{pH} 4.4), 2.5 \mu \mathrm{L} \mathrm{K} \mathrm{Fe}_{3}(\mathrm{CN})_{6}(20 \%)$, and various suitable concentrations of samples were mixed together at $50^{\circ} \mathrm{C}$ for $20 \mathrm{~min}$. After that, $160 \mu \mathrm{L}$ of trichloroacetic acid (TCA) (10\%) was added to the mixture with the centrifugation at $3,000 \mathrm{rpm}$ for $10 \mathrm{~min}$ to collect the supernatant $(75 \mu \mathrm{L}) .25 \mathrm{uL} \mathrm{FeCl}_{3}$ (2\%) was incubated with the supernatant for the optical absorbance measurement at $700 \mathrm{~nm}$. Butyl hydroxyl anisd (BHA) was viewed as a positive control. A higher absorbance value means a better reductive activity [13].

2.6. Cell Cultures. Hs68, HaCaT, B16F10, MeWo, A2058, and A375 cell lines were purchased from the Bioresource Collection and Research Center (BCRC, Hsinchu, Taiwan). Six cells were kept in a cell culture dish at $37^{\circ} \mathrm{C}$ and $5 \% \mathrm{CO}_{2}$ in DMEM supplemented with $10 \% \mathrm{FBS}, 100 \mathrm{U} / \mathrm{mL}$ of penicillin, $100 \mathrm{mg} / \mathrm{mL}$ of streptomycin, and $0.25 \mu \mathrm{g} / \mathrm{mL}$ of amphotericin B [10]. DMSO was dissolved stock solutions of Iso A and Sec A (both at $1.0 \mathrm{M}$ ), and the tested concentrations were prepared by diluting with free medium, and the final DMSO concentration was less than $1.0 \%$ to avoid from unexpected biochemical reactions.

2.7. Cell Proliferation Assay. The cell proliferation effects of Iso $\mathrm{A}$ and Sec A on normal and melanoma cells were tested by MTT assay [14]. This method was based on the property that mitochondrial succinate dehydrogenase from living cells made MTT reduced to water-insoluble blue-violet crystal formazan and deposited in the cells, and dead cells without this function. Briefly, $1 \times 10^{4}$ cells were seeded in a 96-well microplate. After $24 \mathrm{~h}$, discarded the medium, cells were treated with various concentrations $(10,25,50$, and $100 \mu \mathrm{M})$ of Iso A and Sec A or vehicle control in a final volume of $100 \mu \mathrm{L}$ culture medium. The experimental doses were accorded to our previous tests. After cultured within $37^{\circ} \mathrm{C}$, $5 \% \mathrm{CO}_{2}$ incubator for $24 \mathrm{~h}$, we replaced the medium with $100 \mu \mathrm{L}$ fresh broth contained $0.5 \mathrm{mg} / \mathrm{mL}$ MTT. The plate was kept in a $37^{\circ} \mathrm{C}$ incubator for $2 \mathrm{~h}$. We discarded the medium to add $100 \mu \mathrm{L}$ DMSO dissolving the purple formazan crystals and gently shook the plate in darkness for $10 \mathrm{~min}$. The optical absorbance values $(A)$ were measured at $595 \mathrm{~nm}$ (BioTek, WA, USA). Cell viabilities were calcu- lated according to the formula as follows:

$$
\text { Cell viability }(\%)=\frac{\left(A_{\text {sample }}-A_{\text {blank }}\right)}{\left(A_{\text {control }}-A_{\text {blank }}\right)} \times 100 \% \text {. }
$$

2.8. Autophagic Vacuoles Detection by Acridine Orange Staining. B16F10 cells were chosen for the further homologous study to seed in a 6 -well dish at a density of $1 \times 10^{5}$, after $24 \mathrm{~h}$, treated with various concentrations of Iso A and Sec A for $24 \mathrm{~h}$, washed cells twice with PBS, and then incubated with serum-free medium contained $5 \mathrm{ug} / \mathrm{mL}$ acridine orange (AO, Molecular Probes, Eugene, Oregon, USA) at room temperature for $15 \mathrm{~min}$ [15]. We used an inverted fluorescence microscope to obtain the AO fluorescence images. AVO was stained with red color, and the nucleus DNA and cytosolic RNA were stained with green color.

2.9. Annexin V-FITC/PI Binding Assay to Analyze Apoptosis. To further confirm the apoptosis of Iso A and Sec A-treated malignant melanoma B16F10 cells, annexin V-fluorescein isothiocyanate (FITC)/propidium iodide (PI) doublestaining was performed (Biovision, annexin V-FITC apoptosis kit) [16]. $1 \times 10^{5}$ cells were kept in a 6-well dish and were treated with tested Iso A and Sec A concentrations (10, 25, 50 , and $100 \mu \mathrm{M})$ or vehicle control in a total volume of $100 \mu \mathrm{L}$ culture medium for $24 \mathrm{~h}$. We collected the medium, washing twice with PBS to trypsinize the adherent cells. The centrifugation at $1,000 \mathrm{rpm}$ at $4^{\circ} \mathrm{C}$ for $10 \mathrm{~min}$ was set to collect cells and label with annexin V-FITC/PI. The incubation was in darkness for $15 \mathrm{~min}$, and the samples were analyzed by a flow cytometry (Millipore guava easyCyte HT, MA, USA).

2.10. DNA Damage and Cell Cycle Analysis. To identify the phase distribution of cellular DNA, cell cycle analysis was performed as described [17]. B16F10 cells were cultured at a density of $1 \times 10^{5}$ cells in a 6-well dish, and then monolayer cells were treated with various concentrations $(10,25,50$, and $100 \mu \mathrm{M})$ of Iso A, Sec A, or vehicle control for $24 \mathrm{~h}$. Collected adherent and floating cells and washed once with precooled PBS, then fixed cells with precooled $70 \%$ ethanol overnight at $4^{\circ} \mathrm{C}$. After centrifugation at $1,200 \mathrm{rpm}$ for $3 \mathrm{~min}$, wash the cell pellets once with precooled PBS, centrifuged again, and then stained cells with $100 \mu \mathrm{g} / \mathrm{mL}$ RNase and $50 \mu \mathrm{g} / \mathrm{mL}$ PI in PBS buffer, and incubated in darkness at room 
temperature for $30 \mathrm{~min}$. The DNA contents of PI-stained cells were analyzed by flow cytometry.

2.11. Western Blot Analysis. $1 \times 10^{6} \mathrm{~B} 16 \mathrm{~F} 10$ cells were treated with Iso A, Sec A, or vehicle control for $24 \mathrm{~h}$. Cells were harvested and lysed with lysis buffer (Thermo Scientific Pierce RIPA Buffer) to extract cellular proteins. The lysates were centrifuged at $1,2000 \mathrm{rpm}$ for $30 \mathrm{~min}$, and the protein concentrations were measured with the bicinchoninic acid (BCA) protein assay kit (Pierce, Rockford, IL, USA). Sodium dodecyl sulfate-polyacrylamide gel electrophoresis (SDSPAGE) was performed to separate the same amounts of proteins and then electrotransferred the proteins on gel to a polyvinylidene fluoride (PVDF) membrane (PALL Life Science, Ann Arbor, MI, USA). The membrane was blocked with a blocking buffer (Pierce TOOLSpeed PLUS Blocking Reagent) and washed with TBST (Tris-buffered saline, with Tween-20, pH 8.0). The membrane was incubated with the corresponding primary antibody, shaking at $4^{\circ} \mathrm{C}$ overnight, washed three times with TBST and blocked again, and then incubated with secondary antibody against the corresponding primary antibody for $90 \mathrm{~min}$. The signal was visualized by enhanced chemiluminescence (ECL) detection with West Femto Maximum Sensitivity Substrate kit (SuperSignal, Rockford, IL, USA) [12].

2.12. RNA Isolation and Extraction. The RNA was isolated and extracted by Trizol RNA isolation reagent, which could resolve cell lysates and separate RNA, DNA, and proteins. First, $1 \mathrm{~mL}$ Trizol reagent was increased to each and move to the $1.5 \mathrm{~mL}$ microtube at room temperature for $5 \mathrm{~min}$. Then, $200 \mu \mathrm{L}$ BCP per $\mathrm{mL}$ of Trizol reagent was added and mixed intensely [18]. After incubation for $2 \mathrm{~min}$, the samples were centrifuged at $14,000 \times \mathrm{g}$ for $20 \mathrm{~min}$. The sample homogenates formed three phases, from which the aqueous phase on the top of the homogenate was move to a new Eppendorf tube. To precipitate RNA, an equal volume of isopropanol was blended. The mixture was centrifuged at 13,000 $\times \mathrm{g}$ for $15 \mathrm{~min}$, and the supernatant liquid was divided. The RNA pellet was washed with $1 \mathrm{~mL}$ of $75 \%$ ethanol to get rid of the residual salts. In the end, the mixture was centrifuged at $13,000 \mathrm{~g}$ for $5 \mathrm{~min}$, and the RNA pellet was dehydrated and dissolved with $50 \mu \mathrm{L}$ diethylpyrocarbonate- (DEPC-) treated water. The concentration and quality of the RNA extracts were determined by BioTek (Lionheart Technologies, Inc.)

2.13. Quantitative Real-Time Polymerase Chain Reaction ( $q R T-P C R)$. qRT-PCR is a method detected for evaluating gene expression level by measuring the cDNA products after each cycle of PCR increase. For qRT-PCR, a reactive mixture with SYBR Green Master Mix (Qiagen, Valencia, CA, USA) templates and primers was used [4]. All qRT-PCR reactions were finished by a StepOnePlus ${ }^{\mathrm{TM}}$ System. The reactions were carried out according to the following program: cDNA templates were initiated at $95^{\circ} \mathrm{C}$, annealed at $65^{\circ} \mathrm{C}$, and elongated at $70^{\circ} \mathrm{C}$, and all steps were repeated with 40 cycles of enlargement. At the end of the annealing stage of the experiments, fluorescence acquisition was started to determine. The designed forward and reverse primers from $5^{\prime}$ to $3^{\prime}$ used in this experiment are shown in (Table S1).

2.14. Cell Migration Assay. The population of cellular migratory inhibition effect was examined by wound healing assay as described [15] and performed with minor modification. In brief, $5 \times 10^{5}$ cells were seeded in 6 -well plates and grown to complete confluence. We created a clear wound area on a monolayer culture with a $200 \mu \mathrm{L}$ plastic pipette tip to wash once with PBS and then treated with the samples. Afterward, we used a microscope taking photos at time intervals of 0,6 , 12 , and $24 \mathrm{~h}$ to check the wound closure. The cell movement and migration through the wound area were calculated by the free software, ImageJ.

2.15. Animal Material. In this study, the application of animals complied with the guiding principles in the care and use of animals of the American physiology society was approved by the National Chung Hsing University Use Committee (IACUC: 106-111, Figure S1). BALB/c nude female mice (4-5 weeks) were purchased from BioLASCO Experimental Animal Center (Taiwan Co., Ltd) [19, 20]. The mice were housed in plexiglass cages in a temperaturecontrolled room $\left(22 \pm 1^{\circ} \mathrm{C}\right)$, on a $12 \mathrm{~h} / 12 \mathrm{~h}$ light/dark schedule, and with free access to food and water (fed a standard laboratory diet). After one week, 18 mice were randomly divided into 3 groups ( $n=6$, each group): Group A, vehicle blank control; Group B, B16F10 only; and Group $\mathrm{C}, \mathrm{B} 16 \mathrm{~F} 10$ with Iso A treatment.

2.16. Xenograft Tumor Assay. The performance of xenograft tumor assay was described previously with minor modifications. In brief, $\mathrm{BALB} / \mathrm{c}$ nu/nu female mice were housed, and the in vivo experiments were performed at the animal center. Mice were implanted subcutaneously with $1 \times 10^{7}$ of B16F10 homologous cells in $0.1 \mathrm{~mL}$ PBS injected subcutaneously in each mouse [19]. Mice were treated four times a week with a subcutaneous injection of Iso A $(200 \mathrm{mg} / \mathrm{kg})$ until sacrifice at day 35. The diameters of xenograft tumor were measured at 4 days intervals with Vernier calipers and calculated as $\left(\right.$ length $\times$ width $\left.^{2}\right) / 2$ in $\mathrm{mm}^{3}$.

2.17. Histopathological Analyses of Xenografted Tumor. The fresh tumor tissues were made in paraffin, cut into $3 \mathrm{~mm}$ thick chunks, set in plastic cassettes, and immersed in $10 \%$ neutral buffered formalin for 7 days. Staining of sectioned paraffin-embedded tumor tissue with Hematoxylin and Eosin ( $\mathrm{H} \& \mathrm{E})$. This stain is visible for tissue processing, embedding, and sectioning. The range of Iso A-treatment shrunk the tumor weight and volume was evaluated, and the assessment of mitotic cell division in the xenografted tumor fragments was also observed via H\&E images [20].

2.18. Statistical Analysis. Statistical data were shown as mean \pm standard deviation (SD) values, and Student's test was applied to determine the difference between the control vehicle and experimental groups, ${ }^{*} p<0.05$ versus control; ${ }^{* *} p<0.01$ versus control. 


\section{Results}

3.1. Antioxidant Activity of Iso A and Sec A. Since melanomas occur on the skin and most of them are caused by UV exposure, the impacts of oxidative stresses on melanoma have attracted researchers' attentions. Antioxidants are thought to prevent UV-induced oxidative stress and DNA damage, and previous studies have shown that antioxidant intakes can prevent melanoma developments. Therefore, the antioxidant activities of Iso A and Sec A were evaluated (Table 1). At testing concentrations, two constitutes did not show good antioxidant activities, and thus it was speculated that both components did not suppress melanoma proliferation by antioxidative properties.

3.2. Antiproliferative Effects of Iso A and Sec A. This work was aimed at finding the potential agents with antimelanoma effects, and a good leading compound should also be safe enough for normal cells. Thus, the effectivenesses of two components was evaluated on the proliferation of normal human skin cells including fibroblast Hs68 cell line and keratinocyte $\mathrm{HaCaT}$ cell line. Figure 2(a) showed the results from MTT assay of $24 \mathrm{~h}$ treatment at the concentrations of 0 (a vehicle control), 10, 25, 50, and $100 \mu \mathrm{M}$, respectively. All experimental concentrations were at less than $1.0 \%$ DMSO. Iso A presented no cytotoxicity on fibroblasts and minor cytotoxicity on keratinocytes at high concentrations. Sec A demonstrated a slight cytotoxic effect on keratinocytes and fibroblast cells at concentrations of 10 and $25 \mu \mathrm{M}$, respectively, but at the concentrations of 50 and $100 \mu \mathrm{M}$, Sec A influenced the survival of fibroblasts. $\mathrm{IC}_{50}$ (the halfmaximal inhibitory concentration) is the quantitative value of the potency on Iso A or Sec A in the suppression to the specific cellular viability. To evaluate the effects of two compounds on malignant melanomas, the MTT method was also applied on B16F10, MeWo, A2058, and A375 cells (Figure 2(b)). Four melanoma cells were treated with concentrations from 0 to $100 \mu \mathrm{M}$ for $24 \mathrm{~h}$, respectively. The cell proliferation of melanoma cells was inhibited by both compounds in concentration-dependent manners, and the treatments illustrated excellent anticancer effects, especially on B16F10, A2058, and MeWo cells. At the concentrations of 50 and $100 \mu \mathrm{M}$, we observed that more than half of the cells were dead. According to these findings, we chose $\mathrm{B} 16 \mathrm{~F} 10$ as our testing cell line at 25 and $100 \mu \mathrm{M}$ for the further studies.

3.3. The Formation of Autophagic Vacuoles (AVO) in Iso A and Sec A-Treated B16F10 Cells. To identify if Iso A and Sec A treatments will induce autophagic cell death in $\mathrm{B} 16 \mathrm{~F} 10$ cells, $\mathrm{AO}$ staining was performed. $\mathrm{AO}$ is a lysomotropic metachromatic fluorescent dye and can be used to analyze the lysosomal membrane permeability status. During the autophagy process, autophagosome fuses with lysosome to produce autolysosome, phagolysosome, and autophagolysosome. B16F10 cells were incubated with Iso A and Sec A and then labeled with $\mathrm{AO}$ to visualize the acidic vesicular organelles (AVOs) of acidic autophagolysosome. The cell nuclei DNA and cytosol RNA were stained with green color, and AVOs were observed in red color (Figure 2(c)). There was an obvious enhancement of red fluorescence, which indicated that testing samples can induce autophagy on the melanoma cells. In addition, the number of cells was also significantly reduced at high concentrations, pointing out the excellent cytotoxicity in dose-dependent manners.

3.4. Iso A and Sec A Cause Apoptotic Cell Death on B16F10 Cells. The two-dimensional flow cytometry was employed to evaluate the cytotoxic effects of Iso A and Sec A. In the early apoptotic cells, cell membrane surface damage occurs, and the phospholipidine serine (PS) on the inner surface can be reversed to the outer membrane of the cell. Annexin $\mathrm{V}$ is a phospholipid-binding protein with a high affinity for phosphatidylserine and was applied to detect the early cell apoptosis. Propidium iodide (PI) is a nucleic acid dye and was used to label the late apoptotic cells and dead cells. The flow cytometry presented annexin V-FITC staining in $x$ -axis and PI staining in $y$-axis. Briefly, the left lower quadrant means living cells, and the right lower and right upper quadrants mean early and late apoptotic cells, respectively. In addition, the left upper quadrant refers to necrotic cells. B16F10 cells were cultured with various concentrations of Iso A and Sec A or a vehicle control for $24 \mathrm{~h}$ (Figure 3(a)). The treated cells presented obvious apoptosis compared with the vehicle control. Iso A caused significant apoptotic cell death at the concentration of 50 and $100 \mu \mathrm{M}$, and the percentage of late apoptosis cells in the group treated with $50 \mu \mathrm{M}$ Iso A was increased to $64.07 \pm 0.97 \%$ and the group treated with $100 \mu \mathrm{M}$ was increased to $91.51 \pm 0.30 \%$, compared with $5.26 \pm 0.28 \%$ of the control. Sec A presented a concentration-dependent manner to trigger apoptosis mechanism as Iso A to suppress melanoma growth. The group treated with $100 \mu \mathrm{M}$ Sec A induced $46.76 \pm 3.49 \%$ cells to enter late apoptosis, compared with $6.03 \pm 0.78 \%$ of the vehicle control group.

3.5. Iso A and Sec A Induce DNA Damage and Cell Cycle Arrest. The cellular DNA content and cell cycle were tested after the treatments at various concentrations of Iso $\mathrm{A}$ and Sec A for $24 \mathrm{~h}$. B16F10 cells were harvested and washed once with PBS, fixed by precooled $70 \%$ ethanol overnight, stained by PI, and analyzed by the flow cytometry. The accumulation of the G0/G1 population is usually thought as a biomarker of DNA damage and an occurrence of apoptosis [21]. As shown in Figure 3(b), after exposure to Iso A for $24 \mathrm{~h}$, the G0/G1 accumulation arose obviously, and the G2/M profile decreased. To compare with $48.20 \pm 1.3 \%$ on the shape in G0/G1 phase of vehicle control, the treated groups were increased to $48.27 \pm 0.2 \%, 58.30 \pm 0.4 \%, 73.50 \pm 0.1 \%$, and $55.77 \pm 0.9 \%$ at the concentrations of 10,25 , and $50 \mu \mathrm{M}$, respectively. At $100 \mu \mathrm{M}$, alive B16F10 cells were too few to be examined precisely. Sec A induced DNA damage to arise the G0/G1 accumulation which was similar to Iso A performance. We compared with the value of $47.4 \pm 0.6 \%$ in G0/G1 accumulation in the control group; Sec A treatment elevated the other group values to $50.77 \pm 0.6 \%, 58.95 \pm 0.2$ $\%$, and $70.30 \pm 0.8 \%$ in sequence at 10,25 , and $50 \mu \mathrm{M}$. For the same reason, at high dose, B16F10 surface structure and 


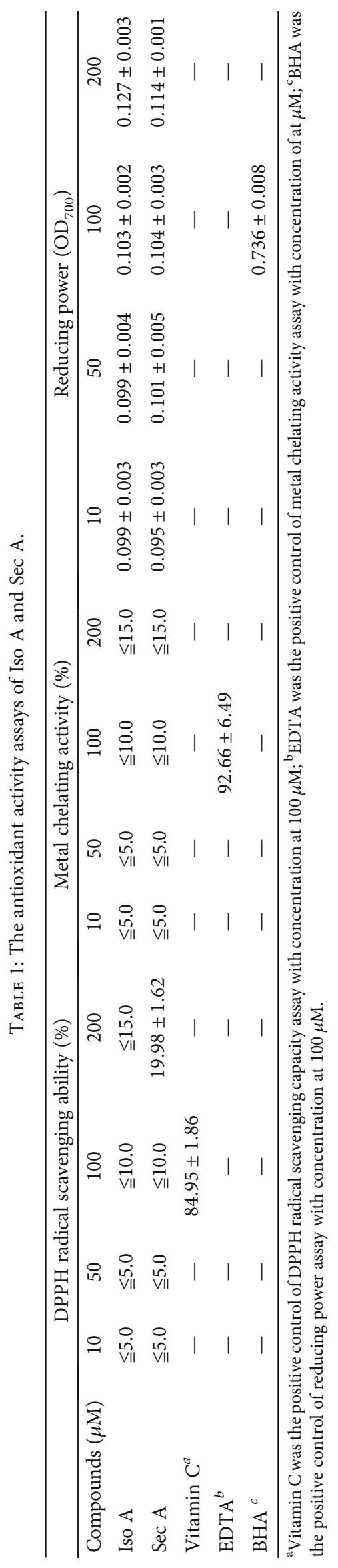



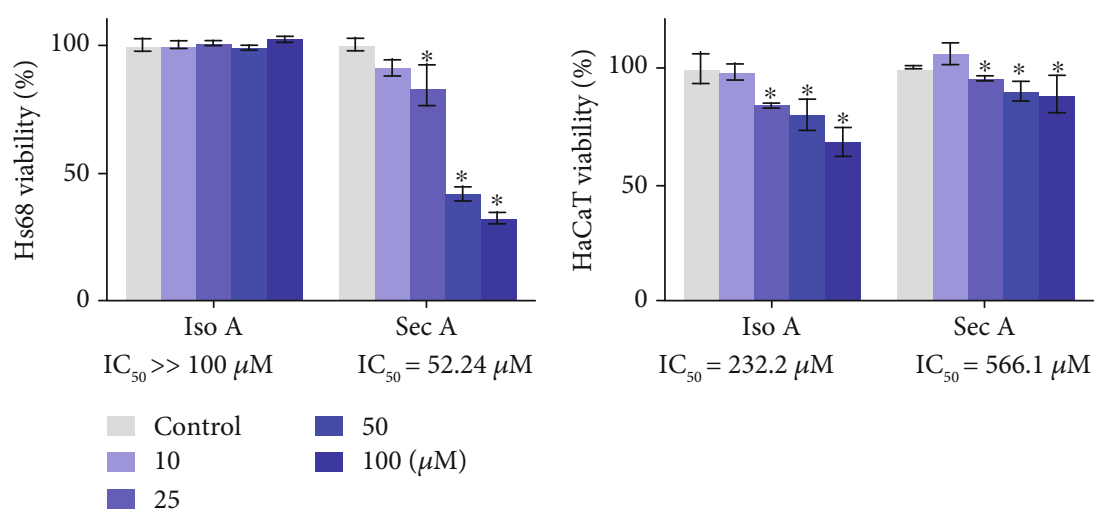

(a)
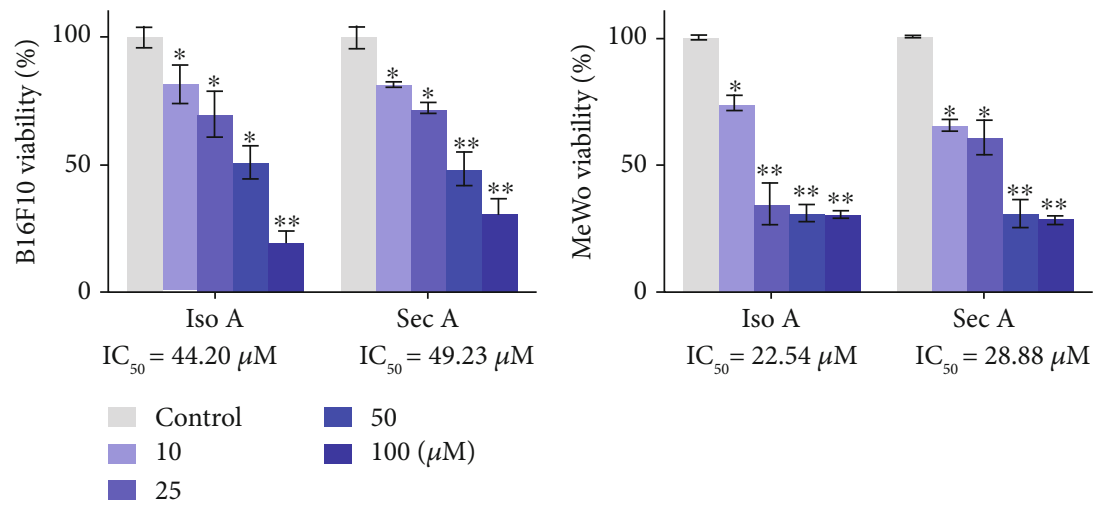

(b)
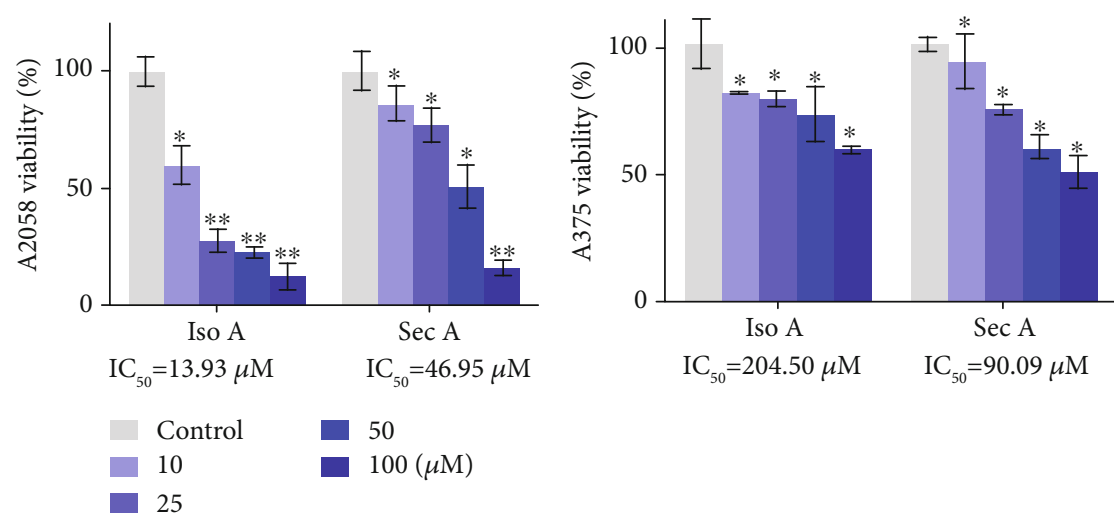

(c)
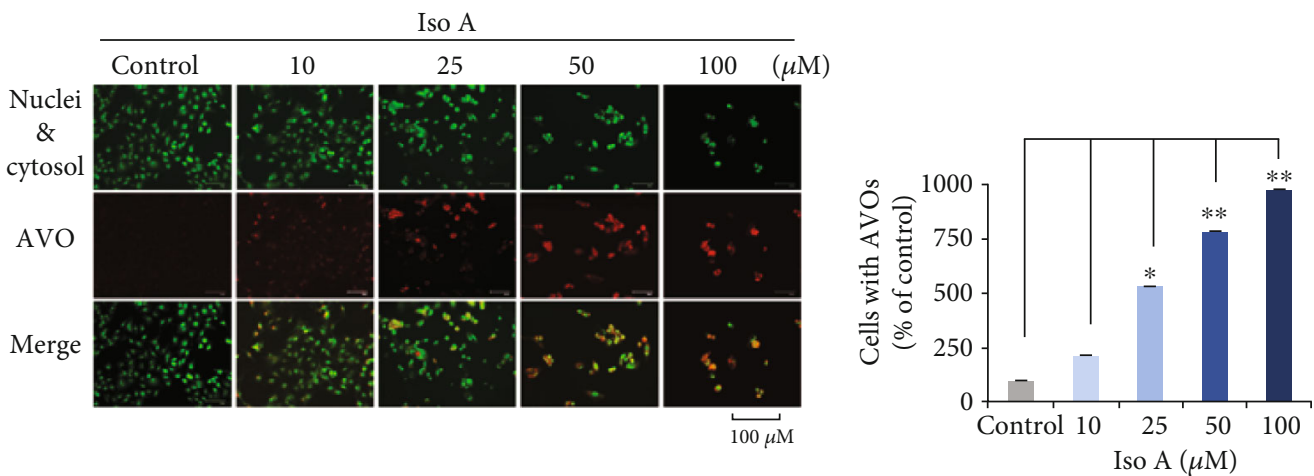

(d)

Figure 2: Continued. 

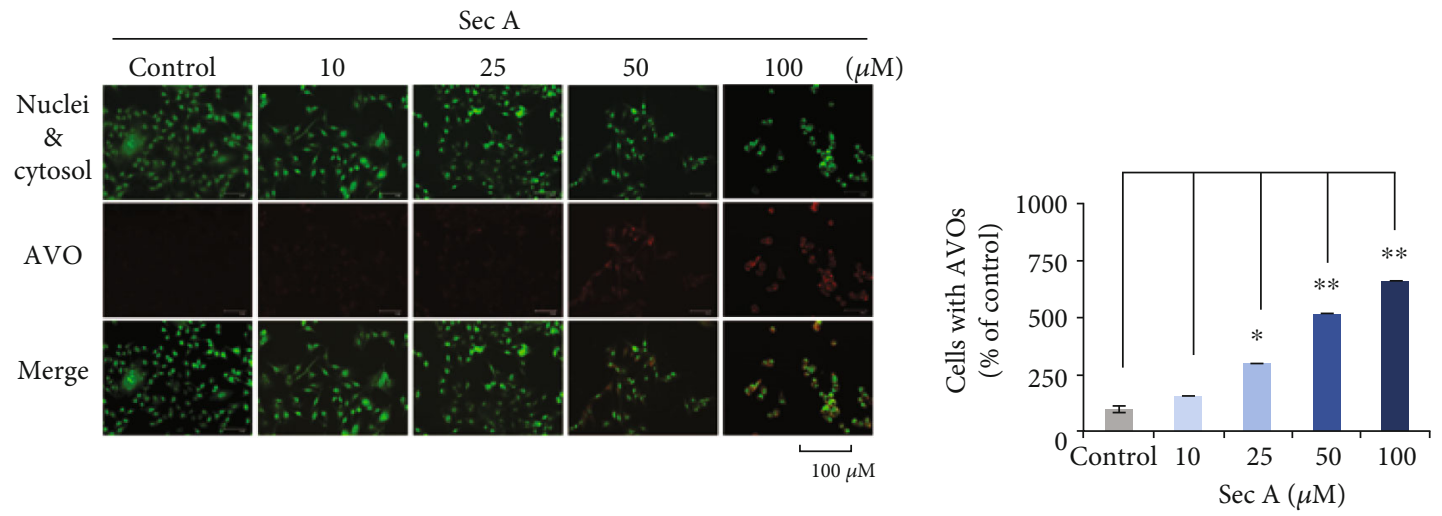

(e)

Figure 2: Effects of Iso A and Sec A on the normal and melanoma cells. (a) HaCaT and Hs68 proliferations after the treatments of Iso A and Sec A for 24 h. (b) Quantifications of B16F10, MeWo, A2058, and A375 cell growth inhibitions in the above conditions, respectively. (c) Fluorescent images of Iso A and Sec A-induced acidic autophagic AVOs. Cells were stained with AO to detect with a fluorescence microscopy. At least three photos were taken in various view versions, and one was chosen as an example to be demonstrated. The data represented mean values $\pm \mathrm{SD}$ of three independent experiments performed. ${ }^{*} p<0.05$ and ${ }^{* *} p<0.01 . n=3$.

DNA integrity were not good to be detected. In addition, the tumor cellular viability was decreased from 10 to $100 \mu \mathrm{M}$ compared with the vehicle control group, which indirectly indicated the dose-dependent anticancer effects.

3.6. The Autophagy-Related mRNA and Protein Expressions. Since the AVO fluorescence enhancement after $24 \mathrm{~h}$ treatment was observed, quantitative real-time polymerase chain reaction (qRT-PCR) and Western blot analyses were conducted to further confirm the autophagy performance in Iso $\mathrm{A}$ and Sec A treated-B16F10 cells. In Figure 4(a), autophagic-related genes were examined, and we chose representative hallmarks to present this mechanism. Here, the transcriptional expressions involved in the programmed cell death signaling pathway were evaluated by the treatments of both experimental groups. It revealed that gene expressions of Atg 3, 6 (Beclin-1), and 12 were enhanced at a low dosage of $25 \mu \mathrm{M}$ (early cell death phase) and decreased at $100 \mu \mathrm{M}$ (late cell death phase). We also demonstrated typical autophagic-related proteins in Figure 4(b) after both compound treatments. Beclin-1, Atg 10, 16, and LC3B expressions were initially increased and then diminished at the concentrations of 25 and $100 \mu \mathrm{M}$, respectively, to show a consistent phenomenon with mRNA expressions. In addition, the expression level of Atg 5 was not upregulated drastically, but diminished significantly. The results presented that at the concentration of $25 \mu \mathrm{M}$, the expressions of mRNA and proteins were higher than that at $100 \mu \mathrm{M}$ to point out in the early phase (lose dose), melanoma triggered a programmed cell death of autophagy.

\subsection{Examining the Apoptotic-Related $m R N A$ and Protein} Expressions. Caspases are a family of cysteinyl aspartaterequiring proteases, which can be activated by proapoptotic stimuli. To additionally investigate the molecular mechanisms underlying the induced apoptosis in the cells, qRTPCR analysis was focused on two panels of related genes in Figure $4(\mathrm{c})$. The tested concentrations were 0 (control, with
DMSO less than $1 \%$, and PBS buffer), 25, and $100 \mu \mathrm{M}$ for Iso $\mathrm{A}$ and Sec A-treated groups, respectively. There was a concentration-dependent extending manner on three genes in comparison to unstimulated counterparts, including caspase 9, Bax, and Bad. Western blot analysis was performed after $24 \mathrm{~h}$ treatment (Figure $4(\mathrm{~d})$ ). Here, the transcriptional expressions involved in the programmed cell death signaling pathway were evaluated of famous apoptotic proteins, JNK, Bcl-2, cyto c, cleavage caspase 9, and 3. Both data demonstrated that at the concentrations of 25 and $100 \mu \mathrm{M}$ (in the late phase, high dosages), there were higher expressions of genes and proteins than the vehicle control group.

3.8. Cell Migration Inhibited by Iso $A$ and Sec A. The cell migration usually plays a significant role in the maintenance of normal human physiology homeostasis. However, for cancer cells, the irregular proliferation of cell migration is usually responsible for the tumor metastasis. The potential migratory inhibition of B16F10 cells by Iso A and Sec A was evaluated by cellular wound healing assay as shown in Figure 5. After the treatments of $24 \mathrm{~h}$, little cells migrated into the center zone between two dash lines of two experimental groups. The cell migration capacities were weakened, and it was concluded that our compounds inhibited the melanoma cellular movements in dose-dependent manners. At the concentrations of 50 and $100 \mu \mathrm{M}$, both compounds also had a cytotoxicity effect on B16F10 cells and influenced the survival of cells. At the concentrations of 10 and $25 \mu \mathrm{M}$, these compounds did not show strong cytotoxicity activities on cells, but the migration abilities were greatly inhibited compared with the vehicle control. This assay indicated that Iso A and Sec A possessed migration inhibitory potentials. Besides that, we will continue to examine the suppression abilities by using transwell assay in the coming future.

3.9. Histopathological and Immunohistochemical Analyses. After the above experimental studies and according to the regulations of 3R (Replacement, Reduction, and 

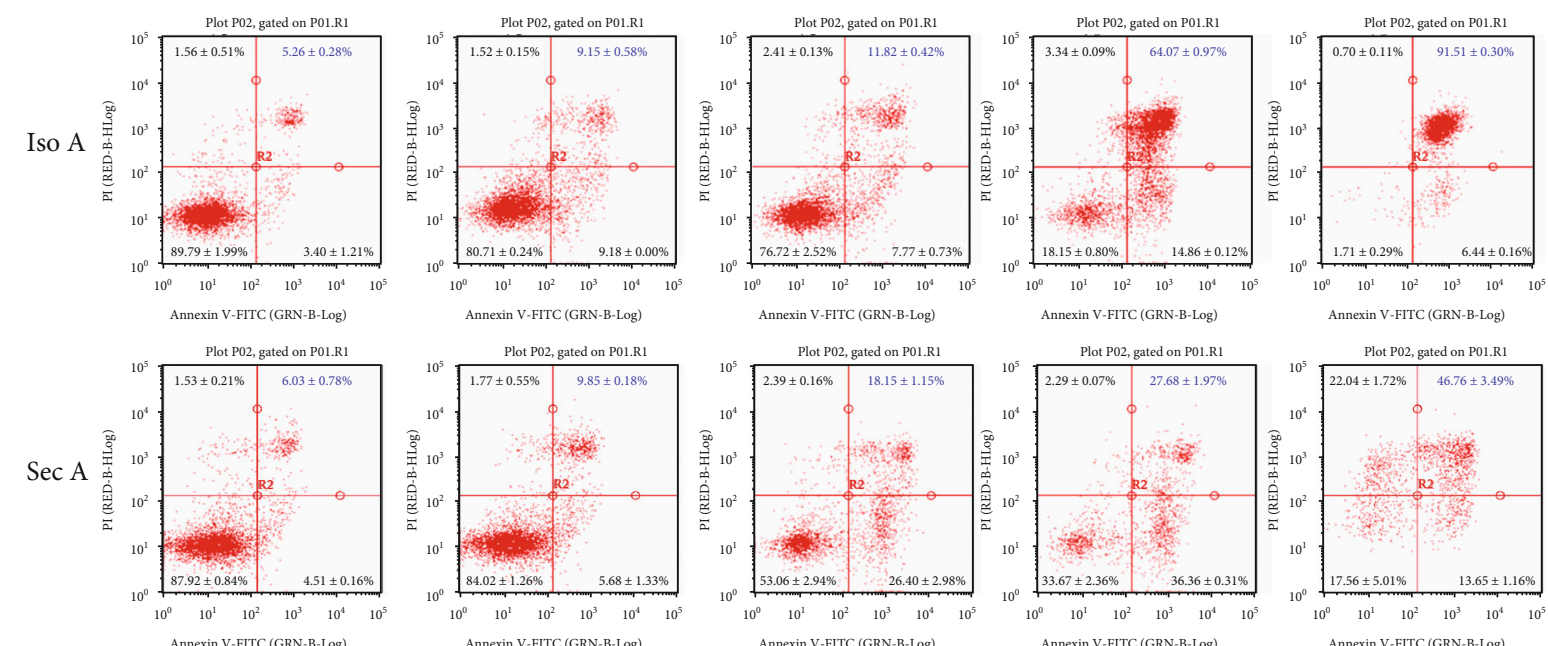

(a)
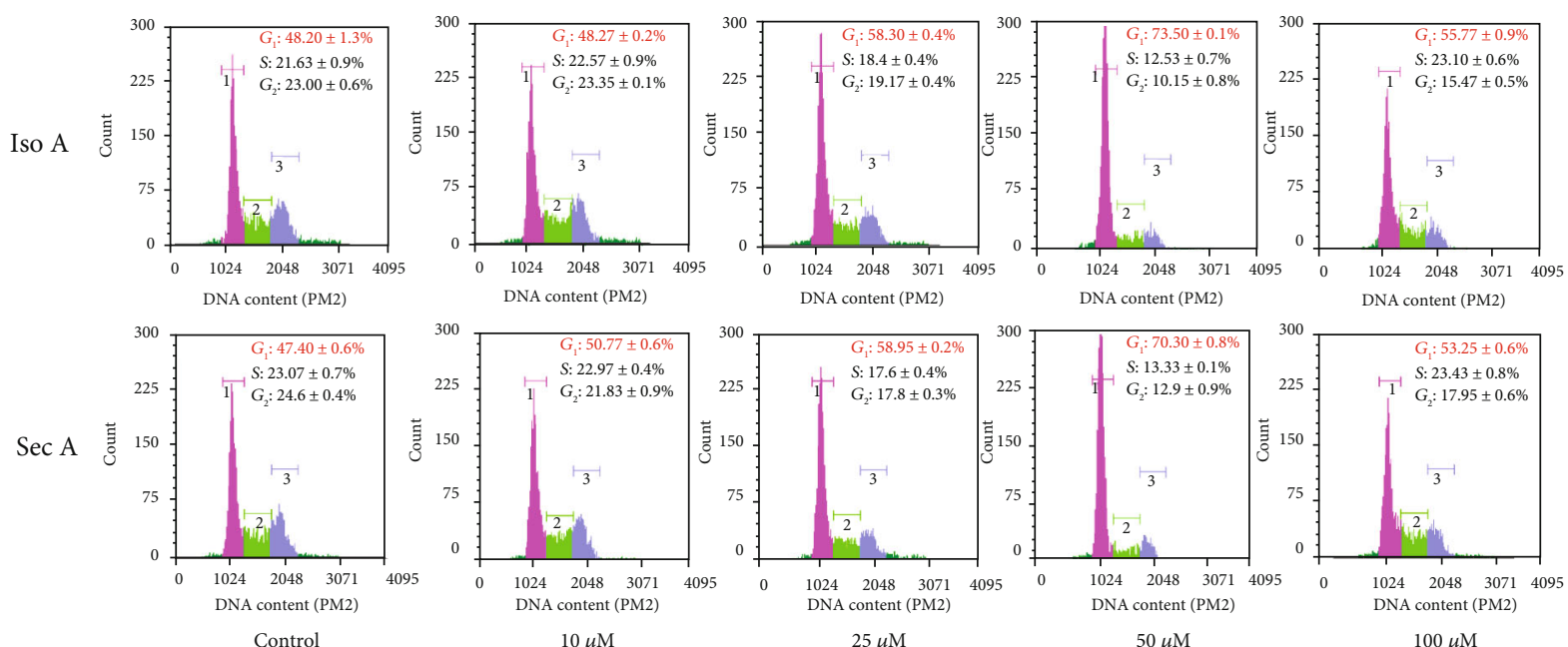

(b)

Figure 3: Cell apoptotic death and cycle distribution in B16F10 cells of Iso A and Sec A. (a, b) Iso A and Sec A induced cell apoptotic death. Apoptosis was analyzed by a flow cytometry after exposed to Iso A from 0 to $100 \mu \mathrm{M}$ for $24 \mathrm{~h}$ and stained with annexin V/PI. (c, d) Effects of Iso $\mathrm{A}$ and Sec A on the cell cycle distribution in B16F10 cells. The cell cycle distribution in Iso A-induced B16F10 cells was determined by the flow cytometry. Cells were administered from 0 to $100 \mu \mathrm{M}$ for $24 \mathrm{~h}$. The data represented mean values \pm SD of three independent experiments performed. $n=3$.

Refinement), we selected Iso A as our unique target compound to work in vivo. The xenograft assay showed that Iso A inhibited the melanoma B16F10 cell growth, and encouragingly, the dissected tumors were visibly smaller in the treatment groups compared to the vehicle group (Figure S2 and Figure 6(a)). We observed mice of the melanoma only group were all dead after four weeks without any therapeutic treatments; in the meantime, the other two group mice were alive with good exercise activity abilities and normal feeding properties. The data demonstrated that Iso A treatment effectively suppressed the tumor growth in the xenograft mice on tumor weight and tumor volume. Furthermore, H\&E staining of the tumor tissues revealed abundant mitosis in the control group, whereas the number of mitosis-positive cells was significantly reduced in the sections from the Iso A treated mice (Figure 6(b)).
To further strengthen our research that Iso A induced autophagy and apoptosis promotes the inhibition of tumor growth in the in vivo examination, the immunohistochemical analyses revealed that the changes in autophagy and apoptosis were noteworthy in xenografted tumor tissues. Iso A treatment significantly increased the LC3B and cleavage caspase 3 expressions (Figure 6(c)). The quantification illustrated that the expression of cleavage caspase 3 was significantly higher than LC3B. Those results were consistent with our in vitro tests and indicated that Iso A induced the autophagy in the early stage and then triggered the cell death through apoptosis pathway.

\section{Discussion}

As a persuasive antimelanoma component, the agent should be harmless on normal cells and without side effects. Thus, 

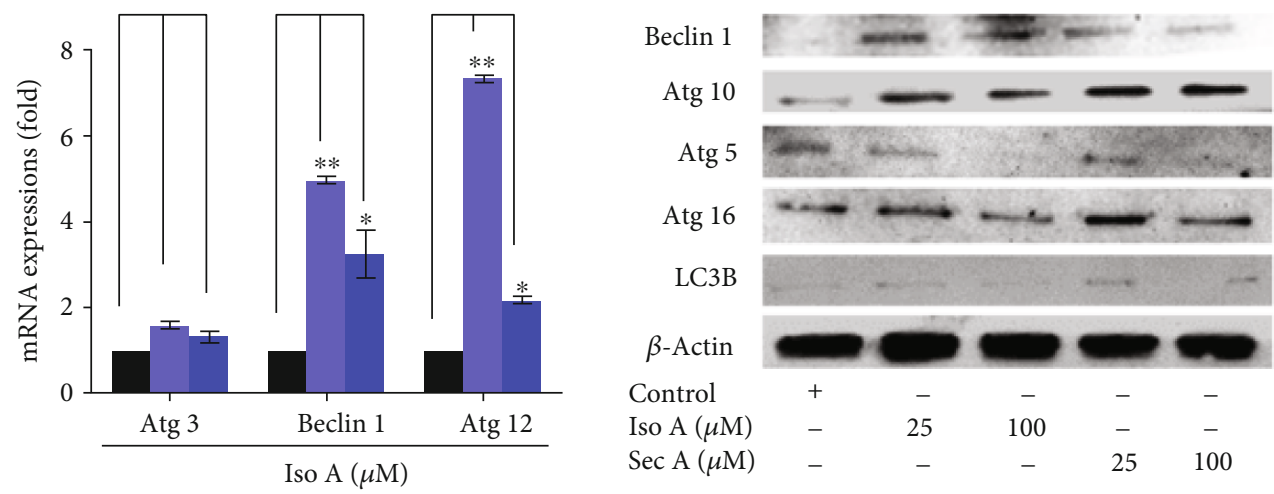

$$
\begin{aligned}
& \text { Control } \\
& 25 \\
& 100(\mu \mathrm{M})
\end{aligned}
$$
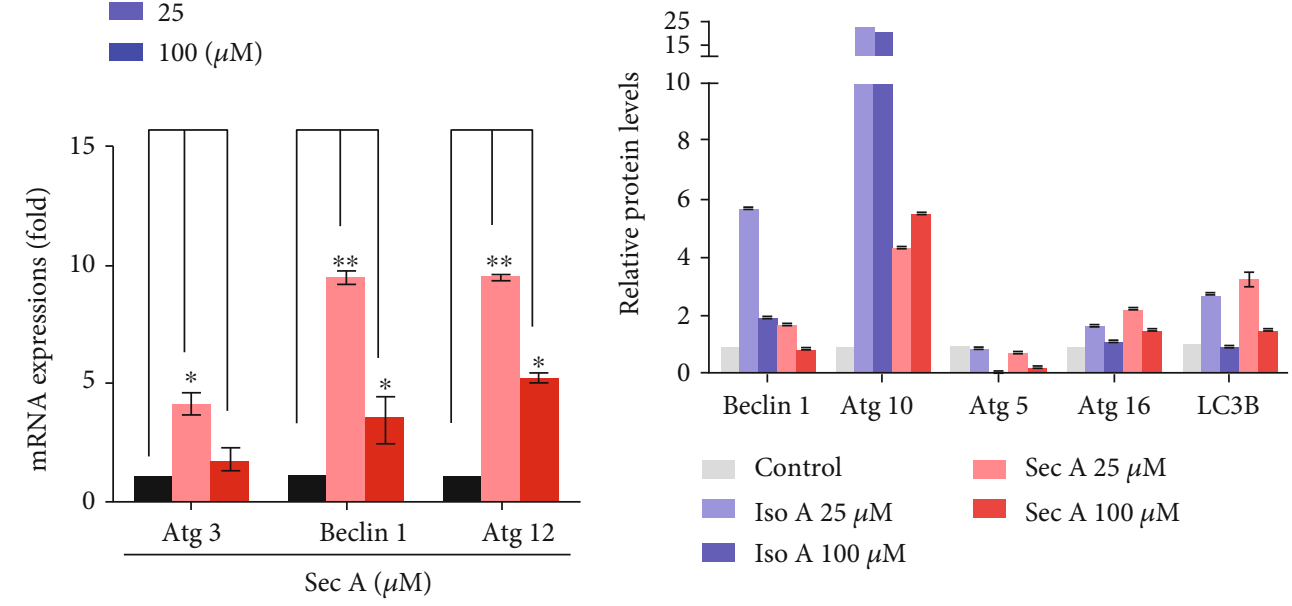

$$
\begin{aligned}
& \text { Control } \\
& 25 \\
& 100(\mu \mathrm{M})
\end{aligned}
$$

(a)

FIgURE 4: Continued. 

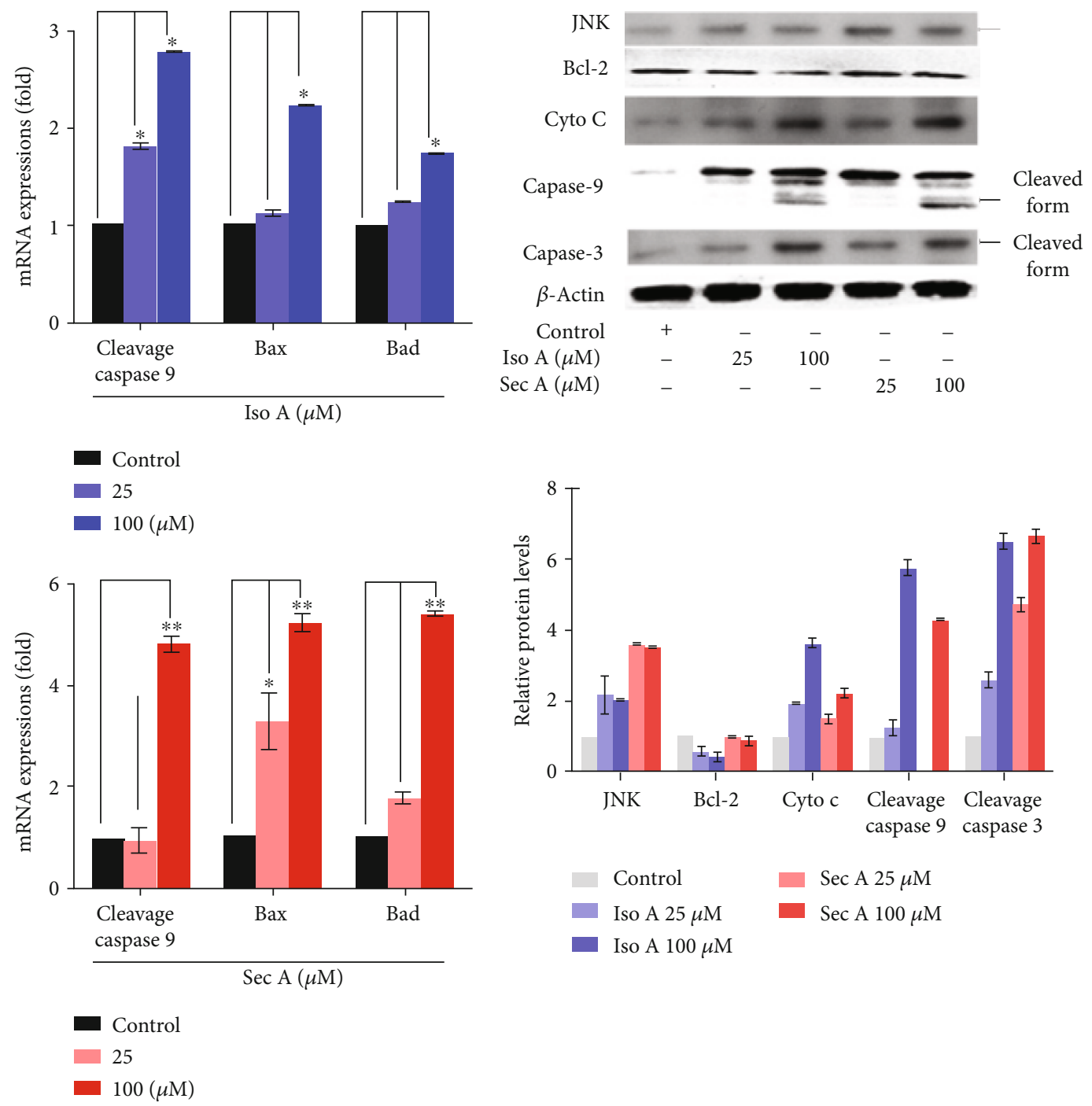

(c)

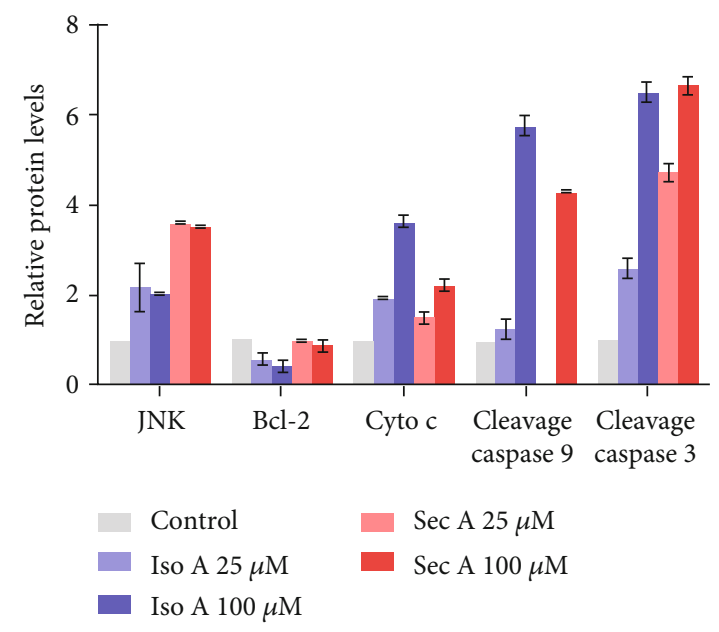

$\operatorname{Sec} \mathrm{A}(\mu \mathrm{M})$

(d)

FIgURE 4: The autophagy and apoptosis-related mRNA and proteins induced by Iso A and Sec A in B16F10 cells. (a) Atg 3, 6, and 12 mRNA expression in B16F10 cells treated with different concentration $(25$ and $100 \mu \mathrm{M})$ was evaluated by the quantitative polymerase chain reaction and normalized to the GAPDH gene. (b) The autophagic-related proteins Beclin 1, Atg 10, 5, and 16 expressions. $\beta$-Actin was viewed as an internal control. (c) The mRNA expression of caspase 9, Bax, and Bad in B16F10 cells treated with different concentrations (25 and $100 \mu \mathrm{M}$ ) was evaluated by the quantitative polymerase chain reaction and normalized to the GAPDH gene. (d) The apoptosis-related proteins JNK, Bcl-2, Cytochrome c, Caspase 9, and 3 expressions in B16F10 cells with or without Iso A and Sec A treatment. $\beta$-Actin was viewed as an internal control. The data represented mean values $\pm \mathrm{SD}$ of three independent experiments performed. ${ }^{*} p<0.05$ and ${ }^{* *} p<0.01$. $n=3$.

the cytotoxicity effect on normal skin cell growth is greatly important. Therefore, the cell viability assays were performed on the normal skin cells including fibroblasts and keratinocytes [22, 23]. Iso $\mathrm{A}$ and $\mathrm{Sec} \mathrm{A}$ are pale yellowish liquid with the molecular formulas of $\mathrm{C}_{13} \mathrm{H}_{20} \mathrm{O}_{3}$ and $\mathrm{C}_{20} \mathrm{H}_{36} \mathrm{O}_{4}$, respectively. Iso A is a butanolide and Sec A is a secobutanolide. It was found that the Sec A inhibited the cell growth of both the melanoma and normal epidermal cells and HaCat keratinocytes cells because of the long-chain chemical structure. As shown in Figure 2(a), Iso A-treated normal cells presented high cell viabilities, thus Iso A may act as a potential anticancer agent. Sec A presented little cytotoxicity on keratinocytes and mild cytotoxicity at the concentrations of 10 and $25 \mu \mathrm{M}$ on the fibroblasts, and when the concentration increased to 50 and $100 \mu \mathrm{M}$, the cytotoxicity on the fibroblasts was also increased. Topical administration can also show good antimelanoma effect and cause less damage to normal cells.

One of the major problems with cancer treatment is the abnormal fast proliferation and metastatic of tumor cells, which also leads to an increase in recurrence and mortality. In this study, to determine the cell proliferation inhibition effects of natural products on melanoma, four melanoma cells including B16F10, A2058, A375, and MeWo were treated with Iso A and Sec A from 0 to $100 \mu \mathrm{M}$ for $24 \mathrm{~h}$. As shown in Figures 2(b) and 2(c), our samples presented inhibitory activities on all four melanoma cells, and the 


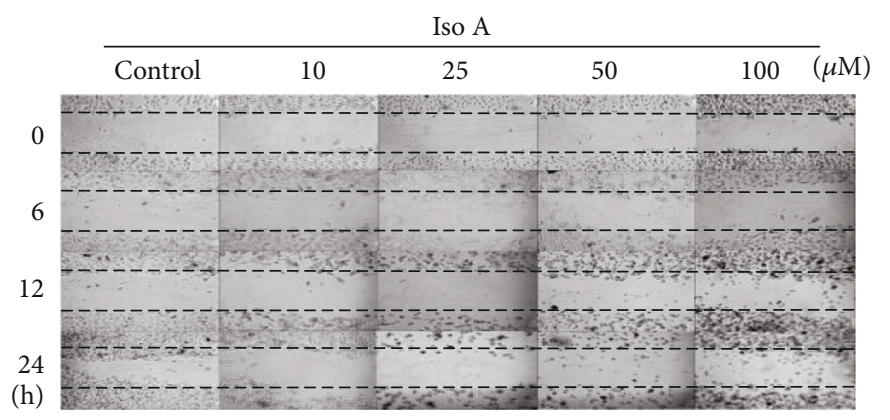

(a)

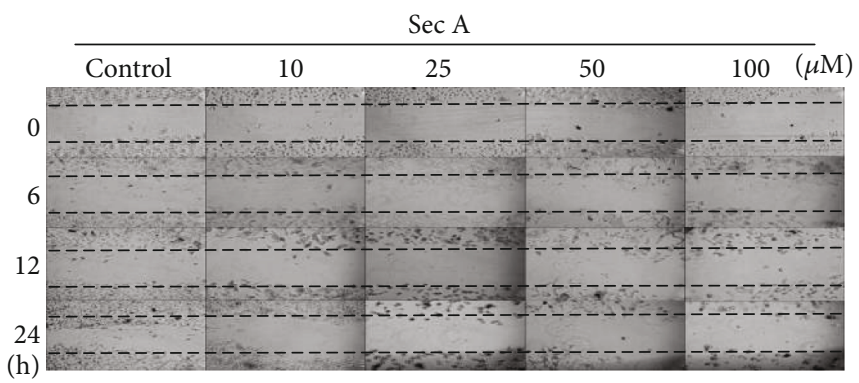

(b)
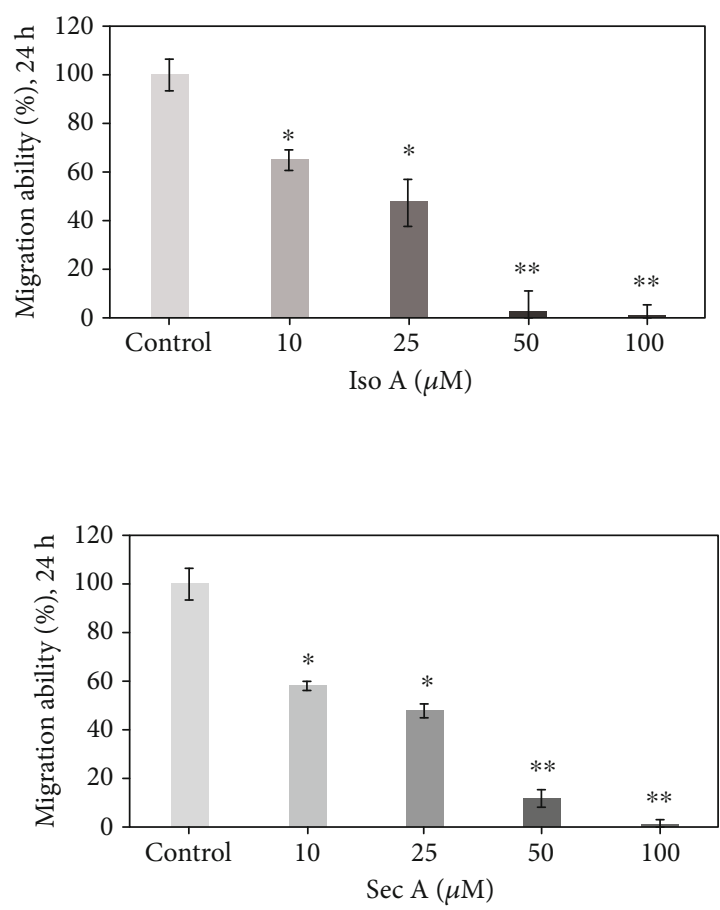

FIgURE 5: In vitro studies of migratory inhibition activities on B16F10 cells by Iso A and Sec A. The effects of migratory suppression were examined by wound healing assay after $24 \mathrm{~h}$ treatment with $0,10,25,50$, and $100 \mu \mathrm{M}$, respectively. The migratory property was quantitatively measured by the software, ImageJ. The data represented mean values \pm SD of three independent experiments performed. * $p$ $<0.05$ and ${ }^{* *} p<0.01$ (the vehicle group was compared as the control standard). $n=3$.

cytotoxicity effects on B16F10, MeWo, and A2058 were relatively stronger. Previous studies have presented that the interaction between cancer cells and the extracellular matrix (ECM) plays an important role in the cell proliferation and migration [24]. Malignant melanoma is one of the most aggressive cancer, but the traditional treatment for metastatic melanoma is limited [25]. Chemotherapies such as fotemustine, dacarbazine, and temozolamide have been used for more than 35 years but are still ineffective in many ways [26]. Therefore, there is an urgent need to find new agents with antimigratory activity. In Figure 5, our results indicated that two compounds reduced the migratory ability of metastatic malignant melanoma cells. In high concentration treatment, the depression of cell migration might also contribute to the cell growth inhibition and cell death. Thus, it will be valuable to examine if Iso $\mathrm{A}$ and $\mathrm{Sec} \mathrm{A}$ can modulate the ECM metabolism process to inhibit the metastasis and invasion of melanoma in the future work $[27,28]$. In the coming future, we will continue to evaluate the migratory suppression via the transwell assay to reveal the detailed mechanism.

We further identified the roles of Atg caspase proteins in the autophagic and apoptotic cells induced by Iso A and Sec $\mathrm{A}$ in malignant melanoma B16F10 cells, and involved mRNA and proteins were examined. On the basis of the cell viability and cell migration assays, it was confirmed that both treatments induced the death of melanoma cells. There are three major types of programmed cell death (PCD): apoptosis, autophagy, and necrosis [29]. In this study, the first two cell death mechanisms were focused on. Autophagy is a conserved catabolic process that digests cytoplasmic components within lysosomes, and it can be triggered by organelle damage, DNA damage, and cell starvation [30]. It is thought as a survival mechanism, which accelerates the degradation of damaged cytoplasmic contents and maintains the cellular homeostasis. However, excessive active autophagy can also lead to cell death. Through AO staining (Figures 2(d) and $2(\mathrm{e})$ ), the performance of autophagy induced by the experimental treatment was initially confirmed, and Western blot analysis identified the autophagic cell death. Autophagy is regulated by a set of Atg proteins. Figures 4(a) and 4(b) revealed that two components enhanced the expressions of Atg 5, 10, 6, and 16 [29].

Among three PCD types, apoptosis is considered as the principal cell death pathway [31]. A series of assays were carried out to identify that the tumor cells are induced by autophagy in the early stage, and then apoptosis is induced by the treatments after the autophagy. Annexin V-FITC/PI double staining presented that in tested concentrations, the fraction radio of late apoptosis cells which were in the right upper quadrant was significantly increased in dosedependent manners (Figures 3(a) and 3(b)). With the purpose of blocking cell proliferation, controlling the cell cycle 

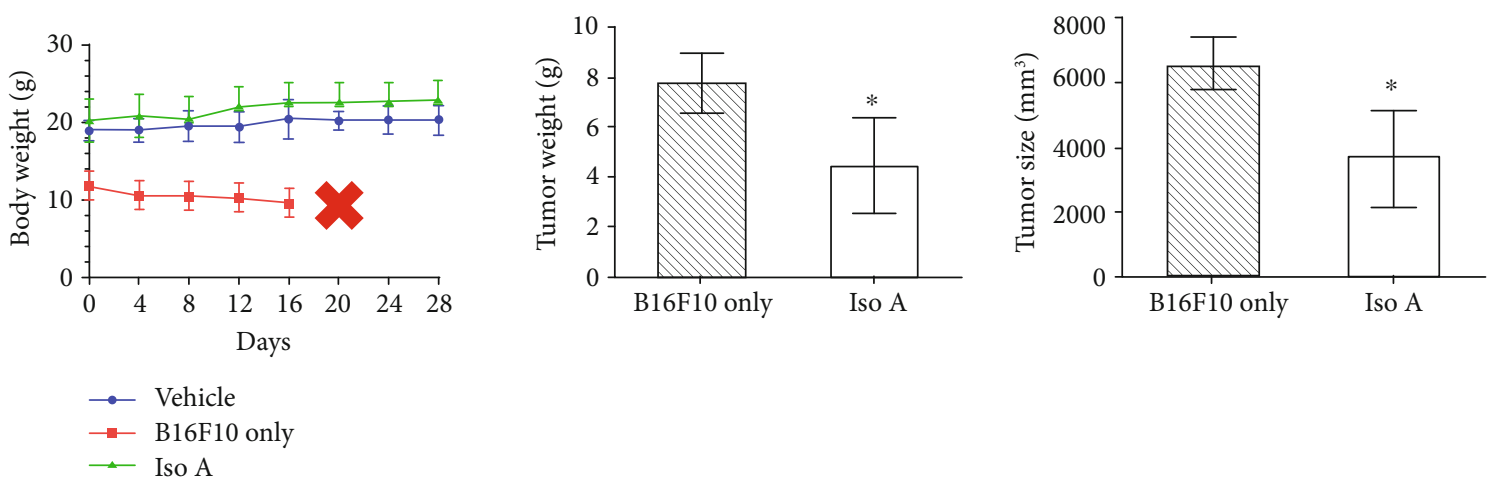

(a)
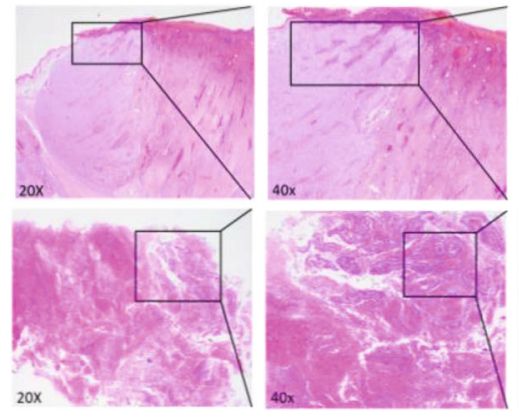

C3B

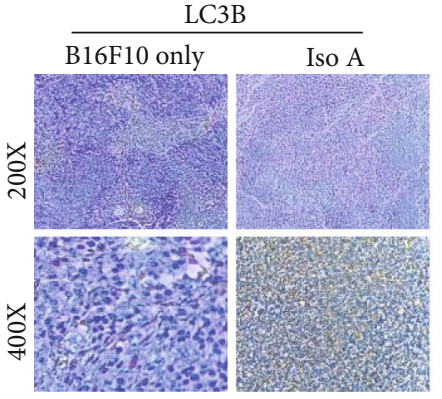

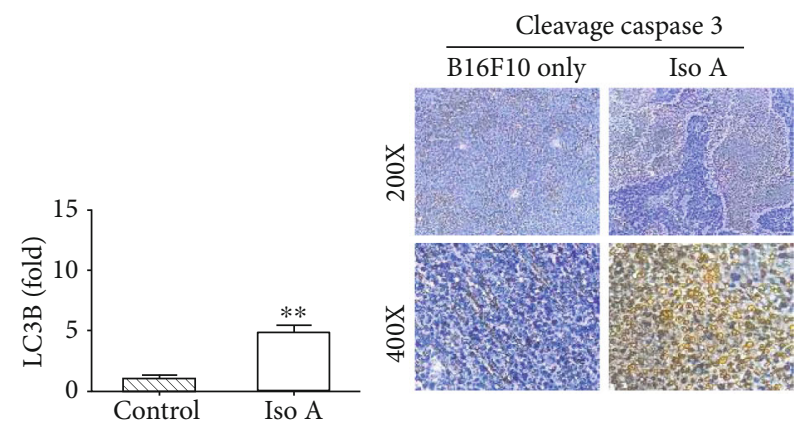
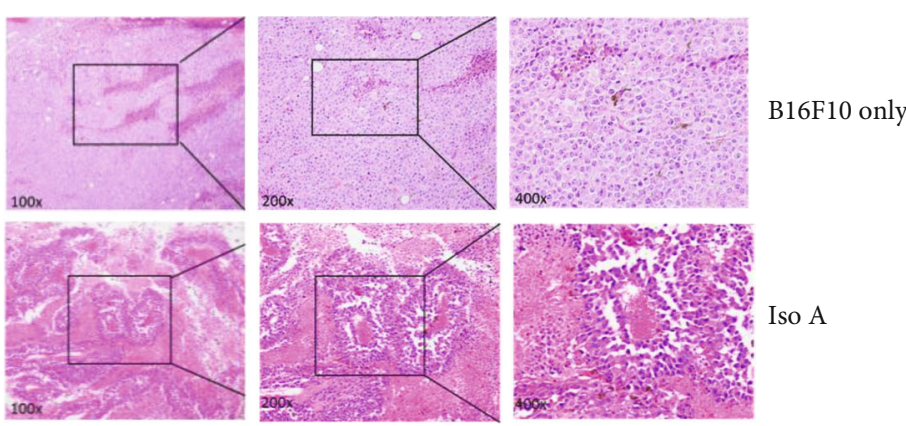

(b)

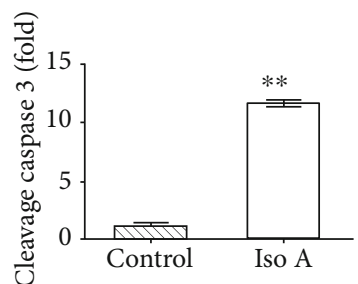

(c)

Figure 6: Animal test and histopathologic analysis of melanoma tumor inhibition (induced by B16F10 cells) treated with Iso A. $n=6$. (a) Antitumor activity of Iso A in nude mice xenograft model. Mice morbidity-free survival efficacy, tumor weight, and tumor volume measurements were demonstrated after sacrifices. (b) H\&E staining of tumor mass of BALB/c mice in the dorsal implant with xenograft B16F10 melanoma tumor cells of Iso A treatment. Smaller tumor mass and tumor cells expressed round to polygonal shapes with several characteristics, including melanin pigment, high mitosis, and central massive necrosis in the mouse. (c) Apoptotic protein LC3B expression and autophagic protein cleavage caspase 3 secretion in tissues treated with/without Iso A detected by immunohistochemistry. The data represented mean values $\pm \mathrm{SD}$ of three independent experiments performed. ${ }^{*} p<0.05$ and ${ }^{* *} p<0.01$.

presents a foremost regulatory mechanism [15]. The cell cycle analysis showed that two treatments stimulated DNA damage, arrested the cell cycle, and induced G2/M accumulation (Figures 6(d) and 6(e)). Caspases play a crucial role in the process of apoptotic cascade. Apoptosis can be triggered by internal or external factors, such as cytotoxic stress, DNA damage, and growth factor withdrawal [32]. In response to those proapoptotic stimuli, the outer membrane of mitochondrial will be damaged and lose the integrity, the permeabilization of mitochondrial will be increased, and the proapoptotic protein cytochrome $\mathrm{c}$ will be released to accelerate the caspase activation [33]. Western blot analysis showed that both treatments triggered the release of cytochrome c, induced the activation of caspase 9, and then caspase 9 stimulated the downstream of caspase 3 (Figures 4(c) and 4(d)) [34]. JNK is an important branch of MAPK pathways, which plays a vital role in cell cycle, reproduction, apoptosis, cell stress, and other physiological and pathological processes. The results indicated that the MAPK signaling pathway might be the apoptosis reaction in those processes (Figure $7(\mathrm{~b})$ ). Bcl-2 is an antiapoptotic protein which can suppress the apoptosis. Previous studies have shown that $\mathrm{Bcl}-2$ could inhibit autophagy by interacting with Bax/Bad and Beclin 1 [35]. The JNK-Bcl-2 pathway 


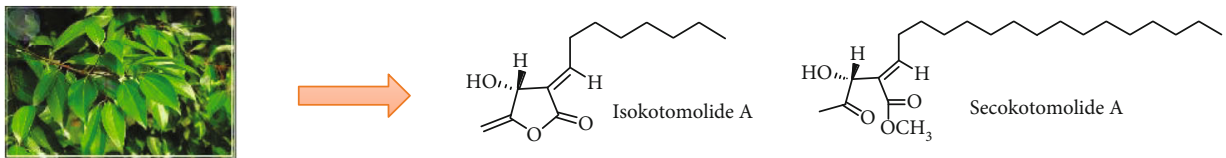

Cell based study

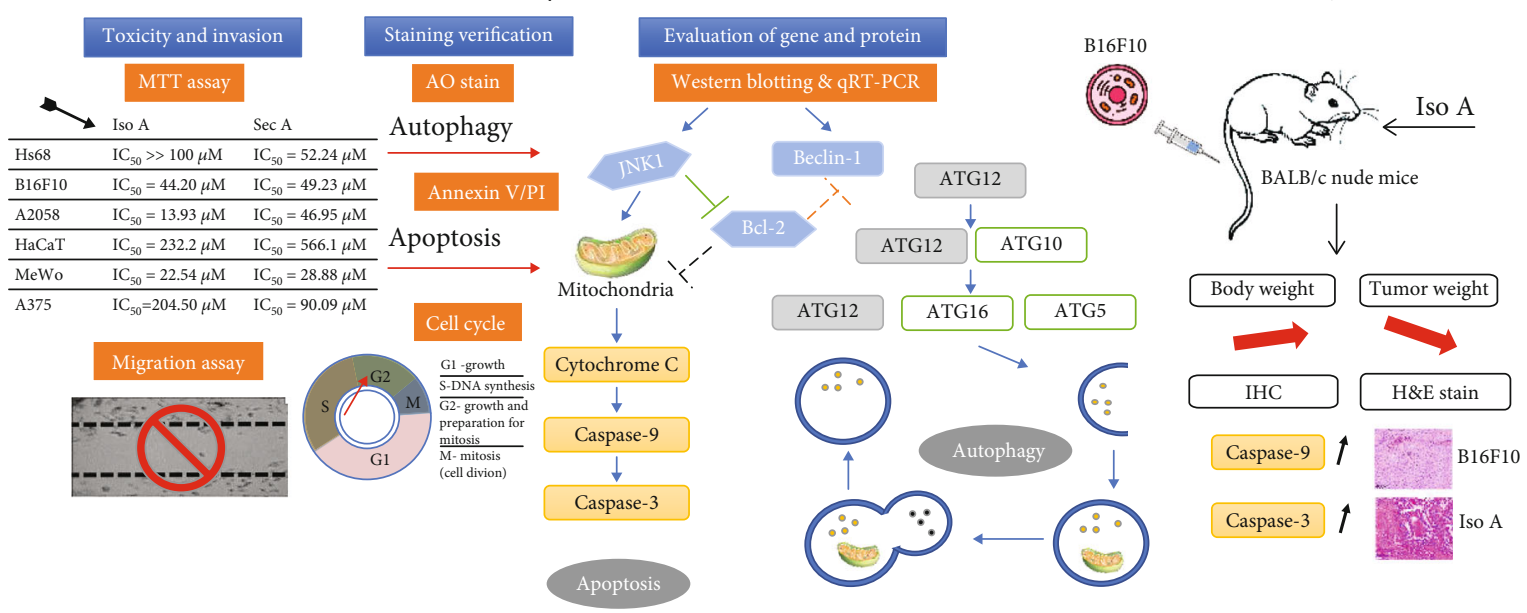

FIGURE 7: Proposed molecular mechanism diagram of $C$. kotoense components inhibit melanoma in vitro and in vivo signaling pathway.

activation can both trigger apoptosis and autophagy [36]. Because autophagy also plays a role in protecting the cells from death stimulus, the interaction between autophagy and apoptosis in Iso A and Sec A-treated cells should undergo advanced investigation.

In vivo research was followed to further boost the antitumor activities of our sample by xenografted BALB/c nude mice. This study demonstrated that Iso A has lower toxicity on normal human skin cells. The treatment via subcutaneous injection in xenografted nude mice resulted in a decrease of the tumor volume during the time course [37, 38]. Histopathological H\&E staining of the tumor tissues demonstrated that there was abundant mitosis in the control group; however, the dorsal implant massive necrosis phenomenon was identified in the tumor sections treated with Iso $\mathrm{A}$ (Figures 6(b) and 6(c)). Smaller tumor mass and tumor cells expressed round to polygonal shapes with melanin pigment, advanced mitosis, and central massive necrosis within the xenografted mice. In summary, in vitro and in vivo examinations confirmed that Iso A and Sec A treatments inhibit the melanoma growth and metastasis effectively in Figure 7.

\section{Conclusions}

Based on the above results, we targeted Iso $\mathrm{A}$ and $\mathrm{Sec} \mathrm{A}$ isolated from Cinnamomum kotoense from a variety of compounds screening with the purpose of melanoma therapy. Both Iso A and Sec A showed biofunctions that induced autophagy in the early stage and induced the cell death through apoptosis in human malignant melanoma and showed a little cytotoxicity on normal skin cells. Histopathological staining and immunohistochemical staining demonstrated that the tumor cell inhibited by Iso A. To our best knowledge, this is the first study of Iso A and Sec A to be potential natural herbal components for human melanoma chemotherapy. Abbreviation within figures: Iso A: isokotomolide A; Sec A: secokotomolide A.

\section{Data Availability}

The datasets generated during and/or analysed during the current study are available from the corresponding author on reasonable request.

\section{Conflicts of Interest}

The authors declare no conflict of interest.

\section{Authors' Contributions}

Jian Li, Chung-Yi Chen, Jyun Yin Huang, Lin Wang, Zixuan $\mathrm{Xu}$, Wenyi Kang, and Hui-Min David Wang performed the experiments and analyzed the data; Jian Li, Chung-Yi Chen, Lin Wang, Wenyi Kang, and Hui-Min David Wang contributed reagents/materials/analysis tools; Jian Li, Chung-Yi Chen, Jyun Yin Huang, Lin Wang, Zixuan Xu, Wenyi Kang, and Hui-Min David Wang wrote the paper. Jian Lil and Chung-Yi Chen contributed equally to this work.

\section{Acknowledgments}

Jyun Yin Huang carried out his thesis research and contributed some results under the auspices of the Master Program in Graduate Institute of Biomedical Engineering, National Chung Hsing University. We also thank Miss Xiao Chung Li (School of Pharmacy, China Pharmaceutical University 211198, China) to assist the experiments. This work was supported by grants from the Ministry of Science and Technology, Taiwan (MOST 108-2221-E-005-044), and we also 
thank the project of Natural Science Foundation of Fujian Province, China (Grant No. 2017J01636).

\section{Supplementary Materials}

Table S1: primers were used for qRT-PCR to analyze the apoptotic and antiapoptotic gene expressions. Figure S1: IACUC certificate of animal examinations (IACUC number: 106111). Figure S2: antitumor activity of Iso $A$ in the xenograft nude mice model via B16F10 melanoma cell model. (Supplementary Materials)

\section{References}

[1] C.-Y. Chen, C.-C. Chiu, C.-P. Wu, Y.-T. Chou, and H.M. Wang, "Enhancements of skin cell proliferations and migrations via 6-dehydrogingerdione," Journal of Agricultural and Food Chemistry, vol. 61, no. 6, pp. 1349-1356, 2013.

[2] A. E. Coghill, L. G. Johnson, D. Berg, A. J. Resler, N. Leca, and M. M. Madeleine, "Immunosuppressive medications and squamous cell skin carcinoma: nested case-control study within the skin cancer after organ transplant (SCOT) cohort," American Journal of Transplantation, vol. 16, no. 2, pp. 565573, 2016.

[3] J. Wang, Y. Zhou, L. Ma et al., "CIAPIN1 targeted NHE1 and ERK1/2 to suppress NSCLC cells' metastasis and predicted good prognosis in NSCLC patients receiving pulmonectomy," Oxidative Medicine and Cellular Longevity, vol. 2019, Article ID 1970818, 15 pages, 2019.

[4] L. C. Lin, C. Y. Chen, C. H. Kuo et al., " $36 \mathrm{H}$ : A novel potent inhibitor for antimelanogenesis," Oxidative Medicine and Cellular Longevity, vol. 2018, Article ID 6354972, 12 pages, 2018.

[5] S. Chummun and N. R. McLean, "Management of malignant skin cancers," Surgery (Oxford), vol. 29, no. 10, pp. 529-533, 2011.

[6] M. El-Kayal, M. Nasr, S. Elkheshen, and N. Mortada, "Colloidal (-)-epigallocatechin-3-gallate vesicular systems for prevention and treatment of skin cancer: a comprehensive experimental study with preclinical investigation," European Journal of Pharmaceutical Sciences, vol. 137, article 104972, 2019.

[7] C. Caddeo, A. Nacher, A. Vassallo et al., "Effect of quercetin and resveratrol co-incorporated in liposomes against inflammatory/oxidative response associated with skin cancer," International Journal of Pharmaceutics, vol. 513, no. 1-2, pp. 153163, 2016.

[8] D. D’Arcangelo, C. Giampietri, M. Muscio, F. Scatozza, F. Facchiano, and A. Facchiano, "WIPI1, BAG1, and PEX3 autophagy-related genes are relevant melanoma markers," Oxidative medicine and cellular longevity, vol. 2018, Article ID 1471682, 12 pages, 2018.

[9] C.-Y. Chen, Y.-L. Hsu, Y.-Y. Chen, J.-Y. Hung, M.-S. Huang, and P.-L. Kuo, "Isokotomolide A, a new butanolide extracted from the leaves of Cinnamomum kotoense, arrests cell cycle progression and induces apoptosis through the induction of p53/p21 and the initiation of mitochondrial system in human non-small cell lung cancer A549 cells," European Journal of Pharmacology, vol. 574, no. 2-3, pp. 94-102, 2007.

[10] C.-H. Chen, W.-L. Lo, Y.-C. Liu, and C.-Y. Chen, "Chemical and cytotoxic constituents from the leaves of Cinnamomum kotoense," Journal of Natural Products, vol. 69, no. 6, pp. 927-933, 2006.

[11] C.-Y. Chen, K.-C. Cheng, A. Y. Chang, Y.-T. Lin, Y.-C. Hseu, and H.-M. Wang, "10-Shogaol, an antioxidant from Zingiber officinale for skin cell proliferation and migration enhancer," International Journal of Molecular Sciences, vol. 13, no. 2, pp. 1762-1777, 2012.

[12] Y. Li, L. Wang, P. Wang et al., "Ginsenoside-Rg1 rescues stress-induced depression-like behaviors via suppression of oxidative stress and neural inflammation in rats," Oxidative medicine and cellular longevity, vol. 2020, Article ID 2325391, 15 pages, 2020.

[13] Y.-T. Chen, C.-J. Kao, H.-Y. Huang et al., "Astaxanthin reduces MMP expressions, suppresses cancer cell migrations, and triggers apoptotic caspases of in vitro and in vivo models in melanoma," Journal of Functional Foods, vol. 31, pp. 20 31, 2017.

[14] P.-H. Li, Y.-P. Chiu, C.-C. Shih et al., "Biofunctional activities of Equisetum Ramosissimum extract: protective effects against oxidation, melanoma, and melanogenesis," Oxidative Medicine and Cellular Longevity, vol. 2016, Article ID 2853543, 9 pages, 2016.

[15] P.-F. Wu, C.-C. Chiu, C.-Y. Chen, and H.-M. D. Wang, "7Hydroxydehydronuciferine induces human melanoma death via triggering autophagy and apoptosis," Experimental Dermatology, vol. 24, no. 12, pp. 930-935, 2015.

[16] H.-M. D. Wang, C.-C. Chen, P. Huynh, and J.-S. Chang, "Exploring the potential of using algae in cosmetics," Bioresource Technology, vol. 184, pp. 355-362, 2015.

[17] H.-J. Zhong, L. Lu, K.-H. Leung et al., “An iridium(III)-based irreversible protein-protein interaction inhibitor of BRD4 as a potent anticancer agent," Chemical Science, vol. 6, no. 10, pp. 5400-5408, 2015.

[18] M. Farrag, S. Abri, and N. D. Leipzig, "pH-dependent RNA isolation from cells encapsulated in chitosan-based biomaterials," International Journal of Biological Macromolecules, vol. 146, pp. 422-430, 2020.

[19] L.-J. Liu, W. Wang, S.-Y. Huang et al., "Inhibition of the Ras/Raf interaction and repression of renal cancer xenografts in vivo by an enantiomeric iridium(III) metal-based compound," Chemical Science, vol. 8, no. 7, pp. 4756-4763, 2017.

[20] D.-L. Ma, L.-J. Liu, K.-H. Leung et al., “Antagonizing STAT3 dimerization with a rhodium(III) complex," Angewandte Chemie, International Edition, vol. 53, no. 35, pp. 9178-9182, 2014.

[21] H. M. Wang, C. C. Chiu, P. F. Wu, and C. Y. Chen, "Subamolide E from Cinnamomum subavenium induces sub-G1 cellcycle arrest and caspase-dependent apoptosis and reduces the migration ability of human melanoma cells," Journal of Agricultural and Food Chemistry, vol. 59, no. 15, pp. 8187-8192, 2011.

[22] C.-C. Wang, S.-Y. Huang, S.-H. Huang et al., "A synthetic biological secondary metabolite, Lycogen ${ }^{\mathrm{TM}}$, produced and extracted from Rhodobacter sphaeroides WL-APD911 in an optimizatioal scale-up strategy," Food Science and Human Wellness, vol. 6, no. 4, pp. 195-201, 2017.

[23] P.-H. Li, L.-H. Liu, C.-C. Chang et al., "Silencing stem cell factor gene in fibroblasts to regulate paracrine factor productions and enhance c-kit expression in melanocytes on melanogenesis," International Journal of Molecular Sciences, vol. 19, no. 5, 2018.

[24] M. Owyong, G. Efe, M. Owyong, A. J. Abbasi, V. Sitarama, and V. Plaks, "Overcoming barriers of age to enhance efficacy of 
cancer immunotherapy: the clout of the extracellular matrix," Frontiers in Cell and Development Biology, vol. 6, 2018.

[25] C. Rong, Z. Yun-Yan, L. Jia-Nan et al., "Ischemic postconditioning alleviates intestinal ischemia-reperfusion injury by enhancing autophagy and suppressing oxidative stress through the Akt/GSK-3 $\beta / \mathrm{Nrf2}$ pathway in mice," Oxidative Medicine and Cellular Longevity, vol. 2020, Article ID 6954764, 14 pages, 2020.

[26] R. J. Davey, A. van der Westhuizen, and N. A. Bowden, "Metastatic melanoma treatment: combining old and new therapies," Critical Reviews in Oncology/Hematology, vol. 98, pp. 242-253, 2016.

[27] H.-Y. Chou, C. Lee, J.-L. Pan et al., "Enriched astaxanthin extract from haematococcus pluvialis augments growth factor secretions to increase cell proliferation and induces MMP1 degradation to enhance collagen production in human dermal fibroblasts," International Journal of Molecular Sciences, vol. 17, no. 6, 2016 .

[28] H. M. Wang, C. L. Kao, W. J. Li, H. T. Li, and C. Y. Chen, "Two new phenylalkanoids from the rhizomes of Zingiber officinale," Chemistry of Natural Compounds, vol. 54, no. 1, pp. 7-9, 2018.

[29] S. Shimizu, T. Yoshida, M. Tsujioka, and S. Arakawa, "Autophagic cell death and cancer," International Journal of Molecular Sciences, vol. 15, no. 2, pp. 3145-3153, 2014.

[30] B. Liu, Z. N. Oltvai, H. Bayır et al., "Quantitative assessment of cell fate decision between autophagy and apoptosis," Scientific Reports, vol. 7, no. 1, article 17605, pp. 1-14, 2017.

[31] Q. Chen, J. Kang, and C. Fu, "The independence of and associations among apoptosis, autophagy, and necrosis," Signal Transduction and Targeted Therapy, vol. 3, no. 1, 2018.

[32] C.-C. Tseng, Y.-J. Lin, W.-T. Liu et al., "Metabolic engineering probiotic yeast produces 3S, 3'S-astaxanthin 3'S-astaxanthin to inhibit B16F10 metastasis," Food and Chemical Toxicology, vol. 135, pp. 110993-1111001, 2020.

[33] L. Hu, Y. Zhang, W. Miao, and T. Cheng, "Reactive oxygen species and Nrf2: functional and transcriptional regulators of hematopoiesis," Oxidative Medicine and Cellular Longevity, vol. 2019, Article ID 5153268, 11 pages, 2019.

[34] G. Blandino, F. Valenti, A. Sacconi, and S. Di Agostino, "Wild type- and mutant p53 proteins in mitochondrial dysfunction: emerging insights in cancer disease," Seminars in Cell \& Developmental Biology, vol. 98, pp. 105-117, 2020.

[35] Y. Chen, J.-Y. Huang, Y. Lin, I.-F. Lin, Y.-R. Lu, and L.-H. Liu, "Antioxidative and antimelanoma effects of various tea extracts via a green extraction method," Journal of Food Quality, vol. 2018, Article ID 5156073, 6 pages, 2018.

[36] J. Yang and S. Yao, "JNK-Bcl-2/Bcl-xL-Bax/Bak pathway mediates the crosstalk between matrine-induced autophagy and apoptosis via interplay with beclin 1," International Journal of Molecular Sciences, vol. 16, no. 10, pp. 25744-25758, 2015.

[37] C.-T. Chang, Y.-C. Hseu, V. Thiyagarajan et al., "Chalcone flavokawain $\mathrm{B}$ induces autophagic-cell death via reactive oxygen species-mediated signaling pathways in human gastric carcinoma and suppresses tumor growth in nude mice," Archives of Toxicology, vol. 91, no. 10, pp. 3341-3364, 2017.

[38] D. Denton, T. Xu, and S. Kumar, "Autophagy as a pro-death pathway," Immunology and Cell Biology, vol. 93, no. 1, pp. 35-42, 2015. 